\title{
Upaya Peningkatan Tata Kelola Perpustakaan Sekolah Dasar Negeri 69 Balang-Balang Sinjai Barat
}

\author{
Taufiq Mathar ${ }^{1}$, Ainun Wardani ${ }^{2}$, Marhani Indah Sari², Zulkifli² ${ }^{2}$ \& Musdalifah ${ }^{2}$ \\ ${ }^{1}$ Dosen Jurusan Ilmu Perpustakaan, Universitas Islam Negeri Alauddin Makassar \\ ${ }^{2}$ Mahasiswa Program S1 Jurusan Ilmu Perpustakaan UIN Alauddin Library, Universitas \\ Islam Negeri Alauddin Makassar \\ Correspondence email: taufiq.m@,uin-alauddin.ac.id
}

\begin{abstract}
Elementary school libraries are an integral part and one of the learning sources in school. Its role in supporting the learning process is highly expected. This paper describes the improvement of library management at SD Negeri 69 Balang-Balang's Library, West Sinjai, based on the practice of fieldwork carried out for almost a month in the location. During that time, direct observation and interaction with the objects were carried out. As result, generally, some of the objects that have been improved are spatial planning and management of collections and other resources in the library. In addition, the library is also suggested to be able to design programs regarding developing reading interest for the students.
\end{abstract}

Keywords: Elemantry school library; management collection

\begin{abstract}
Abstrak
Perpustakaan sekolah dasar menjadi bagian integral dan merupakan salah satu sumber belajar di sekolah. Perannya dalam mendukung proses pembelajaran sangat diharapkan. Tulisan ini mendeskripsikan upaya yang telah dilakukan dalam meningkatkan tata kelola Perpustakaan SD Negeri 69 Balang-Balang Sinjai Barat yang dilakukan selama sebulan praktek kerja lapangan di perpustakaan. Pada masa itu, observasi dan interaksi langsung dengan objek dilakukan. Dari sini, secara garis besar beberapa objek yang ditingkatkan ialah penataan ruang dan manajemen koleksi dan sumber daya lainnya di perpustakaan. Sebagai tambahan, perpustakaan juga akan mengupayakan merancang program-program untuk menumbuhkembangkan minat baca siswa-siswi di sekolah ini.
\end{abstract}

Kata kunci: Perpustakaan sekolah dasar; manajemen koleksi 


\section{A. Pendahuluan}

Perpustakaan sekolah dasar, sebagaimana yang disebutkan pada Peraturan Kepala Perpustakaan Nasional Republik Indonesia Nomor 10 Tahun 2017 Tentang Standar Nasional Perpustakaan Sekolah Dasar/Madrasah Ibtidaiyah ialah "perpustakaan yang berada pada satuan pendidikan formal di lingkungan pendidikan sekolah dasar/madrasah ibtidaiyah yang merupakan bagian integral dari kegiatan sekolah yang bersangkutan, dan merupakan salah satu pusat sumber belajar untuk mendukung tercapainya tujuan pendidikan sekolah yang bersangkutan" (Perpustakaan Nasional Republik Indonesia, 2017). Pengertian tersebut sangat jelas menunjukkan fungsi perpustakaan yang ada pada sekolah dasar yakni sebagai salah satu pusat sumber belajar selain lingkungan keluarga, lingkungan masyarakat, dan tentu saja guru di sekolah.

Sebagai salah satu pusat sumber belajar, maka perpustakaan sekolah dasar semestinya menyediakan bahan-bahan bacaan yang bermutu disertai dengan layanan yang profesional dan selalu menghadirkan program-program yang dapat mendukung proses belajar mengajar di sekolah. Namun masih dapat dijumpai di beberapa perpustakaan sekolah, baik dalam hal kelengkapan bahan bacaannya, tata kelolanya, hingga keberadaannya yang masih perlu mendapatkan perhatian dari beberapa pihak. Untuk itu, setiap perpustakaan sekolah dasar perlu melihat Standar Nasional Perpustakaan 007:2011 (Perpustakaan Nasional Republik Indonesia, 2011), di mana pada standar yang diterbitkan oleh Perpustakaan Nasional RI ini beberapa di antaranya melihat standar koleksi, layanan, sarana dan prasarana, dan tenaga perpustakaan. Setiap poin pada standar tersebut mesti menjadi patokan bagi setiap perpustakaan sekolah dasar/madrasah ibtidaiyah. Dengan berpedoman pada standar tersebut, perpustakaan sekolah yang merupakan bagian integral sekolah dapat berfungsi optimal.

Salah satu perpustakaan sekolah yang menjadi objek kajian ini ialah Perpustakaan SD 69 Balang-Balang di Kabupaten Sinjai Barat, Sulawesi Selatan. Perpustakaan yang didirikan pada tahun 2013 ini berlokasi $\pm 90 \mathrm{~km}$ di bagian selatan Kota Makassar yang dapat ditempuh \pm 3 jam perjalanan melalui jalur darat. Dari pengamatan awal, perpustakaan ini sudah cukup baik sebagai bagian integral sekolahnya, namun pada sisi tata kelolanya masih perlu mendapatkan perhatian lebih. Oleh karena itu, artikel ini menggambarkan peningkatan tata kelola Perpustakaan SD Negeri 69 Balang-Balang sebagai salah satu pusat sumber belajar pada sekolah yang bersangkutan setelah peneliti mengimplementasikan beberapa kegiatan di perpustakaan tersebut. 


\section{B. Metodologi}

Penelitian ini ialah penelitian terapan (applied research) yang dilakukan selama hampir sebulan melakukan praktek kerja lapangan di Perpustakaan SD Negeri 69 Balang-Balang Sinjai Barat, Sulawesi Selatan. Praktek sekaligus riset ini dimaksudkan dapat menawarkan/memberikan solusi dalam meningkatkan tata kelola perpustakaan tersebut. Dalam masa itu, identifikasi dan orientasi awal dilakukan serta interaksi peneliti dengan pustakawan serta pimpinan sekolah dilakukan secara intens agar rancangan agenda kegiatan dapat disusun dan dilaksanakan. Bagian-bagian yang menjadi fokus perhatian ialah penataan ruang perpustakaan, klasifikasi bahan pustaka, pendataan koleksi, shelving, keanggotaan, dan program layanan perpustakaan.

\section{Hasil dan Pembahasan}

Sekolah Dasar Negeri 69 Balang-Balang Sinjai Barat pertama kali didirikan tahun 1950. Sementara untuk perpustakaannya, barulah pada tahun 2013 memiliki gedung tersendiri yang cukup representatif sebagai salah satu tempat belajar di sekolah. Sejak itu, perpustakaan yang menjadi bagian integral dan salah satu sumber belajar di sekolah telah menjalankan fungsi-fungsinya sebagai perpustakaan. Perannya tidak lain yakni mendukung kegiatan pembelajaran di sekolah tersebut apalagi dengan adanya perhatian dan dukungan pimpinan, perpustakaan ini terus berupaya memberikan layanan terbaik kepada penggunanya. Saat ini, perpustakaan dikelola oleh 2 orang pustakawan yang memang telah memiliki latar belakang pada bidang perpustakaan. Dengan bekal pengetahuan itu, perpustakaan ini dapat dikatakan telah dikelola dengan baik dan telah menjalankan fungsinya meskipun dengan keterbatasan perlengkapan dan peralatan pendukung kerjanya di perpustakaan.

Beragam koleksi di perpustakaan juga dihadirkan dan disesuaikan dengan jenjang pendidikan sekolah dasar agar perpustakaan dapat menjadi salah satu sumber belajar di sekolah. Meskipun dari segi jumlahnya masih kurang kaya untuk melayani ratusan siswa-siswa beserta guru di sekolah tersebut. Selain itu, bentuk koleksi perpustakaan juga masih didominasi buku pelajaran yang belum terklasifikasikan dengan baik berdasarkan sistem persepeluhuan Dewey atau Dewey Decimal Classification (DDC) versi elektronik yang digunakan perpustakaan ini.

Berikut ini akan menguraikan kegiatan-kegiatan yang telah dilakukan di Perpustakaan SD Negeri 69 Balang-Balang Sinjai Barat, Sulawesi Selatan guna meningkatkan tata kelolanya. 


\section{Penataan Ruangan}

Ruangan perpustakaan akan melahirkan kesan, baik bagi para pustakawannya maupun penggunanya. Apakah kesan tersebut positif atau negatif, tergantung dari bagaimana penataan dan suasasan ruangan tersebut. Bagi pustakawan, penataan ruangyang baik dapat menciptakan suasana kerja yang nyaman dan efektif. Sementara bagi penggunanya akan menciptakan rasa senang dan nyaman untuk selalu hadir di perpustakaan, sebagaimana yang diungkapkan pada hasilhasil penelitian yang dilakukan oleh Kusdibyo (2010), Anisatun dan Jumino (2017), Mahoni, Suhartika, dan Ginting (2018). Ruangan perpustakaan mesti ditata dengan baik, seperti tata letak rak, meja, ruang baca, dan peralatan/parabot lainnya, guna meningkatkan kinerja sekaligus rasa nyaman kepada pemustaka.

Kondisi penataan ruangan di lokasi penelitian sudah cukup baik, khususnya bagi pustakawan. Namun pada sisi kenyamanan untuk pengunjung dirasakan masih kurang baik, misalnya terlalu sempitnya ruang khusus untuk membaca buku, susunan rak yang kurang tertata rapi, dan sebagainya. Oleh karenanya, setiap peralatan dan perabotan yang ada di perpustakaan, seperti lemari, kursi,

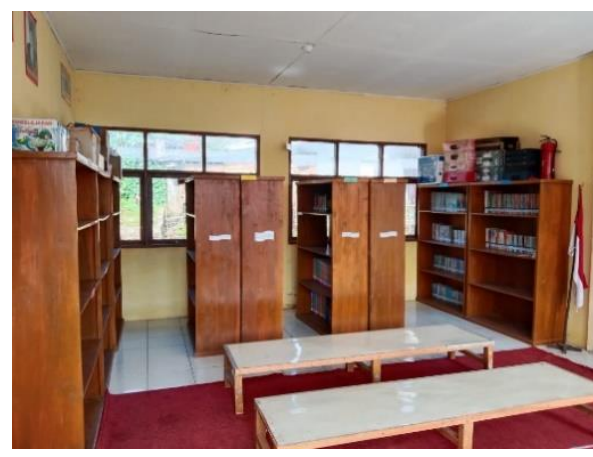

Gambar 1. Ruang perpustakaan setelah ditata ulang dan meja yang ada di perpustakaan ditata ulang dan juga penyediaan ruang bagi siswa-siswi agar dapat menciptakan kenyamanan bagi mereka yang ingin membaca di tempat (lihat gambar 1).

\section{Klasifikasi Bahan Pustaka}

Klasifikasi bahan pustaka merupakan tugas pokok perpustakaan dan ini hal yang penting dalam mengorganisir setiap koleksi yang dimiliki perpustakaan. Prinsip dari klasifikasi bahan pustaka ialah agar bagaimana koleksi-koleksi yang dimiliki terdata dan teroganisir dengan baik agar pada saat dibutuhkan oleh pengguna mudah untuk ditemukan. Electronic Dewey Decimal Classification (e-DDC) merupakan program sistem klasifikasi yang banyak digunakan di perpustakaan di Indonesia. Dengannya, perpustakaan (baca: pustakawan), karena mudahnya digunakan banyak terbantu untuk menentukan nomor klasifikasi setiap koleksi perpustakaan. Banyak perpustakaan sekolah di Indonesia sangat terbantu dengan menggunakan program e-DDC yang dikembangkan oleh Mohamad Rotmianto ini. Beberapa tulisannya di antaranya yang berjudul "Aplikasi e-DDC Edition 22 Sebagai Alternatif untuk Menentukan Nomor Klasifikasi DDC" (Rotmianto , 
2011) dan "e-DDC (electronic-Dewey Decimal Classification) as a freeware classification number finder based on DDC: history and development" (Rotmianto, 2015). Karena mudahnya digunakan, e-DDC telah membantu pustakawan dalam menentukan nomor klas tiap koleksi, berbeda jika dengan langsung merujuk ke buku DDC versi cetaknya. Di perpustakaan ini pun menggunakan aplikasi tersebut.

Beberapa koleksi yang ada di perpustakaan telah memiliki nomor klasifikasi yang diberikan oleh pustakawannya. Namun, masih ada juga beberapa yang belum ada. Karenanya, di masa ini kamipun melanjutkan menambahkan nomor klasifikasi pada setiap koleksi yang belum ada. Selain itu, nomor klas yang ada di setiap buku dirasakan belum membantu perpustakaan untuk dapat cepat meletakannya kembali di rak setelah digunakan pengguna. Maka ditambahkanlah label warna dengan menggunakan lakban seperti yang terlihat pada gambar 2 .

Di atas label nomor klasifikasi pada punggu buku, kami menambahkan 5 warna (lihat tabel di samping) sebagai label pembantu yang maksudnya agar pustakawan dapat lebih cepat mengidentifikasi lokasi rak dari koleksi yang dimaksud. Misalnya label warna merah untuk koleksi buku dengan nomor klas 200 seperti terlihat pada gambar di bawah.

\begin{tabular}{|c|l|c|c|}
\hline No & Warna & Klas & Keterangan \\
\hline 1 & Pink & 000 & $\begin{array}{l}\text { No klas lainnya } \\
\text { belum diberikan } \\
\text { warna karena } \\
\text { jumlahnya yang } \\
\text { tidak sebanyak } \\
\text { klas lainnya }\end{array}$ \\
\hline 2 & $\begin{array}{l}\text { Abu- } \\
\text { abu }\end{array}$ & 100 & \multicolumn{1}{|c|}{} \\
\cline { 1 - 2 } 3 & Merah & 200 & \\
\hline 4 & Biru & 300 & \\
\cline { 1 - 2 } 5 & Hitam & 800 & \\
\hline
\end{tabular}

Warna-warna yang dipilih untuk mendampingi setiap nomor klasifikasi tersebut dipilih atas inisiatif peneliti, yang tujuannya sebagaimana yang disebutkan tadi yakni agar dapat membantu pustakawan untuk lebih cepat melakukan shelving. Beberapa kajian terkait penerapan label warna di beberapa perpustakaan seperti yang dituliskan di kertas karya oleh Tumanggor, (2018) dan Irmawati, (2013). 


\section{Katalogisasi}

Mengatalog bahan pustaka ialah kegiatan mendata atau mencatat atau mendeskripsikan setiap koleksi yang dimiliki perpustakaan. Katalog juga merupakan bagian penting dan tidak terpisahkan pada setiap perpustakaan. Katalog perpustakaan dulunya berbentuk katalog kartu yang berukuran 12,5 x 7,5 cm. Seiring dengan berkembangnya bidang teknologi, katalog kartu di beberapa perpustakaan mengalami transformasi ke bentuk katalog online atau yang dikenal dengan OPAC (Online Public Access Catalog). OPAC perpustakaan sudah banyak diterapkan di berbagai macam jenis perpustakaan, misalnya yang dituliskan oleh (Rahayu, Satria, \& Cahyana, 2012), (Jamil, 2015), (Wiradani \& Ardoni, 2013), dan (Saufa \& W, 2017). OPAC biasanya dijumpai di perpustakaan yang telah menerapkan sistem manajemen perpustakaan berbasis teknologi.

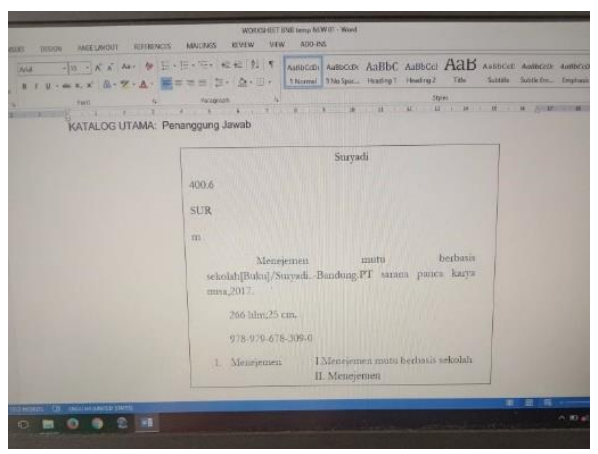

Gambar 3. Katalog kartu dibuat dengan program Ms. Word

Perpustakaan ini belum menggunakan sistem manajemen perpustakaan berbasis teknologi (biasa diistilahkan sebagai sistem automasi perpustakaan) dalam mengelola sumber daya yang dimiliki perpustakaan. Sistem-sistem manajemen perpustakaan berbasis IT yang ada saat ini biasanya telah menyediakan katalog, baik dalam format kartu ataupun versi OPAC.

Dikarenakan keterbatasan sarana

yang ada, katalogisasi bahan pustaka dilakukan degan menggunakan program Ms. Word untuk membuat katalog perpustakaan (lihat gambar 3). Katalog tersebut dibuat sesuai dengan jumlah koleksi yang dimiliki perpustakaan saat ini seperti yang terlihat pada gambar berikut. Pembuatan katalog kartu atau kartu katalog perpustakaan dengan cara seperti ini dilakukan di masa lalu, ketika sistem atau program-program manajemen perpustakaan berbasis teknologi belum hadir di perpustakaan. Namun kini, sistem semacam ini telah banyak dan dapat kami sarankan agar perpustakaan ini ke depan nanti dapat menerapkannya. Hal ini penting bagi tiap perpustakaan, termasuk perpustakaan sekolah, di mana pada salah satu standar yang telah dirilis oleh Perpustakaan Nasional RI ialah agar sebaiknya perpustakaan dikelola dengan memanfaatkan TIK. 


\section{Keanggotaan}

Perpustakaan tanpa pengguna perpustakaan tidak dapat dikatakan sebagai perpustakaan. Pengguna atau anggota perpustakaan sesungguhnya ialah pemilik dari perpustakaan tersebut. Oleh karenanya, mereka mesti mendapatkan pelayanan yang baik. Salah satu bentuk yang menandakan bahwa seseorang dikatakan sebagai anggota perpustakaan ialah dengan adanya kartu keanggotaan.

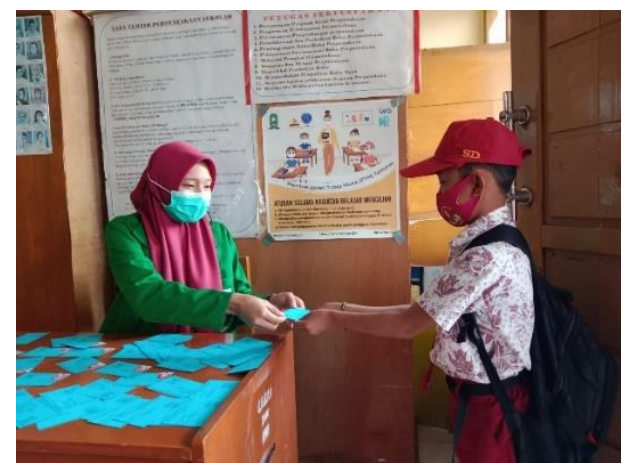

Gambar 4. Kartu anggota perpustakaan diberikan kepada seorang siswa

Umumnya dengan kartu tersebut, pengguna telah dinyatakan terdaftar dan dapat menggunakan layanan yang tersedia di perpustakaan. Maka itu, kartu anggota perpustakaan dibuatkan. Sama halnya kartu katalog, kartu anggota perpustakaan juga dibuat dengan menggunakan program Ms. Word yang selanjutnya dicetak pada kertas karton berwarna biru muda (lihat gambar 4).

\section{Program Layanan Perpustakaan}

Pada umumnya di setiap perpustakaan sekolah telah memberikan layanan baca bagi pemustaknya. Adapun untuk program-program yang di luar dari pemandangan umum seperti itu masih sangat kurang dijumpai, misalnya program literasi informasi, literasi media, dongeng, dan sebagainya. Demikian halnya di perpustakaan ini, layanan yang diberikan masih seperti pada umumnya di perpustakaan sekolah. Oleh karena itu, telah diwacanakan untuk menghadirkan program menumbuhkembangkan minat baca bagi siswa-siswa di sekolah tersebut yang diharapkan nantinya dapat diwujudkan di sekolah ini. Perpustakaan yang ada saat ini meski memusatkan perhatiannya agar bagaimana koleksi yang ada di perpustakaan dimanfaatkan oleh penggunanya. Program ini tentunya membutuhkan keahlian tersendiri bagi pustakawannya karena mereka harus mengenal dan memahami bagaimana kiat-kiat menumbuhkembangkan minat baca tersebut. Ini merupakan tantangan bagi perpustakaan khususnya bagi pustakawannya sendiri agar layanan yang diberikan dapat lebih prima.

\section{Kesimpulan}

Sebagai bagian integral dan salah satu sumber belajar di sekolah, Perpustakaan SD Negeri 69 Balang-Balang Sinjai Barat telah berusaha memaksimalkan/meningkatkan perannya. Keterbatasan peralatan dan perabot 
kerja tentunya mempengaruhi peningkatan tata kelola di perpustakaan ini. Oleh karenya di masa yang akan datang dapat diupayakan untuk menghadirkan sarana tersebut. Adapun untuk tata kelola perpustakaan yang dibenahi yakni mulai dari penataan ruangannya hingga pengorganisasian koleksi yang dimiliki perpustakaan, juga pendataan anggota perpustakaan dengan mencetakkan kartu anggota bagi seluruh siswa-siswa di mana mereka adalah pemilik sesungguhnya perpustakaan bersama dengan seluruh guru dan tenaga kependidikan. Programprogram peningkatan atau menumbuhkembangkan juga mendapatkan perhatian khusus di sekolah ini di masa yang akan datang agar peran perpustakaan sekolah bisa lebih maksimal mendukung peran guru membantu mencerdaskan setiap siswa-siswi yang ada di sekolah.

\section{Ucapan terima kasih}

Terima kasih banyak kami haturkan kepada bapak Suardi, S.Pd (kepala sekolah), ibu Jumriah, A.Ma. Pust (kepala perpustakaan) dan Rahmi Indriani, S.I.P (pustakawan), ibu Baderiah, S.Pd serta seluruh tenaga pendidik dan tenaga kependidikan SD Negeri 69 Balang-Balang Kabupaten Sinjai Barat Sulawesi Selatan yang dengan kehangatan mereka semua menerima kami untuk melakukan praktek sekaligus riset di tempat ini.

\section{Daftar Pustaka}

Anisatun, N., \& Jumino. (2017). Tanggapan pemustaka terhadap tata ruang di Perpustakaan Kantor Perwakilan Bank Indonesia Provinsi Jawa Tengah. Jurnal Ilmu Perpustakaan, 6(3).

Irmawati. (2013). Implementasi label warna pada SLiMS versi 5 (Meranti) dalam sistem klasifikasi DDC di Perpustakaan SD Negeri Kotagede 3 Yogyakarta. Yogyakarta: UIN Sunan Kalijaga Yogyakarta.

Jamil, A. S. (2015). Efektivitas penggunaan katalog online (OPAC) di Perpustakaan Universitas Negeri Malang. Jurnal Administrasi Publik, 3(3).

Kusdibyo. (2010). Upaya mewujudkan tata ruang praktis dan pelayanan perpustakaan yang representatif. Jurnal STIE Semarang, 2(1), 79.

Mahoni, P. A., Suhartika, I. P., \& Ginting, R. T. (2018). Pengaruh redesain tata ruang perpustakaan terhadap minat kunjungan pemustaka di Perpustakaan Universitas Warmadewa. Jurnal Ilmiah D3 Perpustakaan, 1(1).

Perpustakaan Nasional Republik Indonesia. (2011). Standar Nasional Perpustakaan Sekolah 07:2011. Jakarta: Perpustakaan Nasional Republik Indonesia. 
Perpustakaan Nasional Republik Indonesia. (2017). Peraturan Kepala Perpustakaan Nasional Republik. Indonesia Nomor 10 Tabun 2017 Tentang Standar Nasional Perpustakaan Sekolah Dasar/Madrasah Ibtidaiyah. Jakarta: Perpustakaan Nasional Republik Indonesia.

Rahayu, S., Satria, E., \& Cahyana, R. (2012). Pengembangan aplikasi katalog online di Perpustakaan Sekolah Tinggi Teknologi Garut. Jurnal Algoritma, 9(2).

Rotmianto, M. (2011). Aplikasi e-DDC Edition 22 sebagai alternatif untuk menentukan nomor klasifikasi DDC. Visi Pustaka, 13(2).

Rotmianto, M. (2015). E-DDC (electronic-Dewey Decimal Classification) as a freeware classification number finder based on DDC: histroy and development. Media Pustakawan, 22(3).

Saufa, A. F., \& W, J. W. (2017). Evaluasi sistem temu kembali informasi OPAC Perpustakaan Universitas Muhammadiyah Surakarta (UMS). Khizanah al-Hikmah : Jurnal Ilmu Perpustakaan, Informasi, dan Kearsipan, 5(2).

Tumanggor, P. S. (2018). Penerapan label berwarna dalam proses shelving koleksi mancanegara pada Perpustakaan Nasional RI. Sumatera Utara: Universitas Sumatera Utara.

Wiradani, O., \& Ardoni. (2013). Desain katalog online dalam kepuasan pemustaka di Perpustakaan Universitas Negeri Padang. Jurnal Ilmu Informasi Perpustakaan dan Kearsipan, 2(1). 